\title{
Phthalate and non-phthalate plasticizers in indoor dust from childcare facilities, salons, and homes across the USA
}

bikram subedi

Murray State University, bsubedi@murraystate.edu

Kenneth D. Sullivan

Murray State University

Birendra Dhungana

Baylor University, birendra_dhungana@baylor.edu

Follow this and additional works at: https://digitalcommons.murraystate.edu/faculty

Part of the Analytical Chemistry Commons, Environmental Chemistry Commons, Environmental Health and Protection Commons, and the Environmental Monitoring Commons

\section{Recommended Citation}

subedi, bikram; Sullivan, Kenneth D.; and Dhungana, Birendra, "Phthalate and non-phthalate plasticizers in indoor dust from childcare facilities, salons, and homes across the USA" (2017). Faculty \& Staff Research and Creative Activity. 13.

https://digitalcommons.murraystate.edu/faculty/13 


\title{
Phthalate and non-phthalate plasticizers in indoor dust from childcare facilities, salons, and homes across the USA
}

\author{
Bikram Subedi ${ }^{\text {a, }}{ }^{*}$, Kenneth D. Sullivan a , Birendra Dhungana b \\ a Department of Chemistry, Murray State University, Murray, KY, 42071, United States \\ ${ }^{\mathrm{b}}$ Department of Environmental Science, Baylor University, Waco, TX, 76798, United States
}

\section{A R T I C L E I N F O}

\section{Article history:}

Received 4 March 2017

Received in revised form

6 July 2017

Accepted 10 July 2017

\section{Keywords:}

Plasticizers

Phthalates

Non-phthalates

Indoor dust

Daily intake

Childcare facilities

Homes

Salons

\begin{abstract}
A B S T R A C T
The quality of indoor environment has received considerable attention owing to the declining outdoor human activities and the associated public health issues. The prolonged exposure of children in childcare facilities or the occupational exposure of adults to indoor environmental triggers can be a culprit of the pathophysiology of several commonly observed idiopathic syndromes. In this study, concentrations of potentially toxic plasticizers (phthalates as well as non-phthalates) were investigated in 28 dust samples collected from three different indoor environments across the USA. The mean concentrations of nonphthalate plasticizers [acetyl tri- $n$-butyl citrate (ATBC), di-(2-ethylhexyl) adipate (DEHA), and diisobutyl adipate (DIBA)] were found at $0.51-880 \mu \mathrm{g} / \mathrm{g}$ for the first time in indoor dust samples from childcare facilities, homes, and salons across the USA. The observed concentrations of these replacement non-phthalate plasticizer were as high as di-(2-ethylhexyl) phthalate, the most frequently detected phthalate plasticizer at highest concentration worldwide, in most of indoor dust samples. The estimated daily intakes of total phthalates $(n=7)$ by children and toddlers through indoor dust in childcare facilities were 1.6 times higher than the non-phthalate plasticizers $(n=3)$, whereas estimated daily intake of total non-phthalates for all age groups at homes were 1.9 times higher than the phthalate plasticizers. This study reveals, for the first time, a more elevated ( 3 folds) occupational intake of phthalate and nonphthalate plasticizers through the indoor dust at salons ( 214 and $285 \mathrm{ng} / \mathrm{kg}$-bw/day, respectively) than at homes in the USA.
\end{abstract}

๑) 2017 Elsevier Ltd. All rights reserved.

\section{Introduction}

Phthalates, esters of phthalic acids, have been used as plasticizers in diverse applications including children's toys, food containers, personal care products, medical devices, electronics, PVC floorings, and building materials at a single percent to tens of percent levels (Ma et al., 2014). Phthalates are semi-volatile organic compounds and do not chemically bound to the host polymer, therefore, are prone to leach from the plastic materials. The leached phthalates partition to the indoor air $(\log K o a=6.70-12.56)$ and

Abbreviations: ATBC, acetyl tri- $n$-butyl citrate; BBP, butyl benzyl phthalate; DBP, di-n-butyl phthalate; DEHA, di-(2-ethylhexyl) adipate; DEHP, di-(2-ethylhexyl) phthalate; DEP, diethyl phthalate; DIBA, di-isobutyl adipate; DIBP, di-isobutyl phthalate; DMP, dimethyl phthalate; DOP, di-n-octyl phthalate.

th This paper has been recommended for acceptance by Maria Cristina Fossi.

* Corresponding author. Department of Chemistry, Murray State University, 1201 Jesse D. Jones Hall, Murray, KY, 42071, United States.

E-mail address: bsubedi@murraystate.edu (B. Subedi). indoor materials ( $\log K o c=1.68-5.27)$ including indoor dust (Table 1). A thin layer of dust on the impervious surface in indoor environment was found to accumulate several organic contaminants (Bi et al., 2015; Liu et al., 2003). Therefore, indoor dust can be a sink and a repository for many indoor environmental contaminants including phthalates (Butte and Heinzow, 2002).

The occurrence and fate of phthalates in the indoor environment depends on several factors including usage, leachability, the volume of indoor air, the exchange rate of air (Fromme et al., 2004), moisture content (Hsu et al., 2017), interior surface/material composition (Jeon et al., 2016), and indoor temperature (Bi et al., 2015; Jeon et al., 2016). For example, the absorbed phthalate concentration in cotton and polyester clothes was found $\sim 3$ fold higher at $30{ }^{\circ} \mathrm{C}$ than at $21^{\circ} \mathrm{C}$ in a test house in Austin, TX (Bi et al., 2015). However, overall contamination profile of commonly observed phthalates in the environment varies across the world (Guo and Kannan, 2011; Kang et al., 2012). DEHP is the most frequently detected $(\sim 100 \%)$ phthalate in indoor dust, and is reportedly the most dominant phthalate contaminant in indoor dust in USA, 
Table 1

Structures and physicochemical properties of target phthalates and non-phthalates plasticizers.

\begin{tabular}{|c|c|c|c|c|c|c|c|c|c|}
\hline Analytes & Molecular structure & $\begin{array}{l}\text { Molecular } \\
\text { formula }\end{array}$ & $\begin{array}{l}\text { Mol. } \\
\text { Wt. }\end{array}$ & CAS & $\begin{array}{l}\text { Water } \\
\text { solubility }^{\mathrm{a}}\end{array}$ & $\begin{array}{l}\text { Log } \\
K_{\mathrm{oa}}{ }^{\mathrm{b}}\end{array}$ & $\begin{array}{l}\log \\
K_{\mathrm{oc}}{ }^{\mathrm{C}}\end{array}$ & $\begin{array}{l}\log \\
K_{\text {ow }}\end{array}$ & VP $(\text { Pascal })^{\mathrm{e}}$ \\
\hline \multicolumn{10}{|l|}{ Non-phthalate plasticizers } \\
\hline $\begin{array}{l}\text { di-iso-butyl adipate (DIBA) or hexanedioic acid, bis(2- } \\
\text { methylpropyl) ester }\end{array}$ & & $\mathrm{C}_{14} \mathrm{H}_{26} \mathrm{O}_{4}$ & 258.4 & $\begin{array}{l}141- \\
04-8\end{array}$ & 5.649 & 7.850 & 3.1115 & 4.19 & 0.751 \\
\hline di-(2-ethylhexyl) adipate (DEHA) or di-octyl adipate & & $\mathrm{C}_{22} \mathrm{H}_{42} \mathrm{O}_{4}$ & 370.6 & $\begin{array}{l}103- \\
23-1\end{array}$ & $5.452 \mathrm{E}-04$ & 12.871 & 5.2853 & 8.12 & $4.27 \times 10^{-4}$ \\
\hline acetyl tri-n-butyl citrate (ATBC) or (Citroflex A- $4^{\circledR}$ ) & & $\mathrm{C}_{20} \mathrm{H}_{34} \mathrm{O}_{8}$ & 402.5 & $\begin{array}{l}77-90- \\
7\end{array}$ & 0.6464 & 12.101 & 4.9428 & 4.29 & $6.07 \times 10^{-4}$ \\
\hline \multicolumn{10}{|l|}{ Phthalate plasticizers } \\
\hline dimethyl phthalate (DMP) & & $\mathrm{C}_{10} \mathrm{H}_{10} \mathrm{O}_{4}$ & 194.2 & $\begin{array}{l}131- \\
11-3\end{array}$ & 2014 & 6.694 & 1.6789 & 1.66 & 0.263 \\
\hline diethyl phthalate (DEP) & & $\mathrm{C}_{12} \mathrm{H}_{14} \mathrm{O}_{4}$ & 222.2 & $\begin{array}{l}84-66- \\
2\end{array}$ & 287.2 & 7.023 & 2.1325 & 2.65 & $6.48 \times 10^{-2}$ \\
\hline di-iso-butyl phthalate (DIBP) & & $\mathrm{C}_{16} \mathrm{H}_{22} \mathrm{O}_{4}$ & 278.3 & $\begin{array}{l}84-69- \\
5\end{array}$ & 5.061 & 8.412 & 3.0673 & 4.46 & $4.73 \times 10^{-3}$ \\
\hline di-n-butyl phthalate (DBP) & & $\mathrm{C}_{16} \mathrm{H}_{22} \mathrm{O}_{4}$ & 278.3 & $\begin{array}{l}84-74- \\
2\end{array}$ & 2.351 & 8.631 & 3.2830 & 4.61 & $4.73 \times 10^{-3}$ \\
\hline benzyl-butyl phthalate (BBP) & & $\mathrm{C}_{19} \mathrm{H}_{20} \mathrm{O}_{4}$ & 312.6 & $\begin{array}{l}85-68- \\
7\end{array}$ & 0.9489 & 9.018 & 3.4102 & 4.84 & $2.49 \times 10^{-3}$ \\
\hline bis-(2-ethylhexyl) phthalate (DEHP) & & $\mathrm{C}_{24} \mathrm{H}_{38} \mathrm{O}_{4}$ & 390.6 & $\begin{array}{l}117- \\
81-7\end{array}$ & $1.132 \mathrm{E}-03$ & 12.557 & 4.9977 & 8.39 & $2.52 \times 10^{-5}$ \\
\hline di-n-octyl phthalate (DOP) & & $\mathrm{C}_{24} \mathrm{H}_{38} \mathrm{O}_{4}$ & 390.6 & $\begin{array}{l}117- \\
84-0\end{array}$ & $4.236 \mathrm{E}-04$ & 12.079 & 5.2743 & 8.54 & $2.52 \times 10^{-5}$ \\
\hline
\end{tabular}

a Water solubility $\left(\mathrm{mg} / \mathrm{L}, 255^{\circ} \mathrm{C}\right)$ estimated from Log Kow using the US Environmental Protection Agency's EPISuite ${ }^{\mathrm{TM}}$, [WSKOWWIN v1.41].

b Log octanol-air partition coefficient $\left(25^{\circ} \mathrm{C}\right)$ estimated using the US Environmental Protection Agency's EPISuite ${ }^{\mathrm{TM}}$, [KOAWIN v1.10].

c Corrected Log soil adsorption coefficient estimated from Log $K_{\text {ow }}$ values using the US Environmental Protection Agency's EPISuite ${ }^{\mathrm{TM}}$, [KOCWIN v2.00].

${ }^{\mathrm{d}}$ Log octanol-water partition coefficient $\left(25^{\circ} \mathrm{C}\right)$ estimated using the US Environmental Protection Agency's EPISuite ${ }^{\mathrm{TM}}$, [KOWWIN v1.67].

e Vapor pressure for phthalate and non-phthalate plasticizers (Cousins and Mackay, 2000) and the US Environmental Protection Agency's EPISuite ${ }^{\mathrm{TM}}$, respectively.

Germany, and China (Fromme et al., 2004; Guo and Kannan, 2011; Kanazawa et al., 2010; Kang et al., 2012; Ma et al., 2014; Rudel et al., 2003). However, DBP (geometric mean concentration $=7860 \mu \mathrm{g} / \mathrm{g}$ ) was the major phthalate contaminant in indoor dust in Bulgaria (Kolarik et al., 2008).

The contaminant in indoor dust including plasticizers can be an important marker of indoor exposure and public health (Ma et al., 2014; Mendell and Heath, 2005; Whitehead et al., 2011). The acute or chronic exposure of dialkyl ortho-phthalates can cause several adverse effects on human health including irreversible changes in the reproductive system (Kay et al., 2013, 2014) and cognitive performance in school children (Hutter et al., 2013). Exposure of plasticizers can be particularly critical for children due to the developmental juncture and a higher daily intake per unit body mass than adults due to children's higher hand-mouth activities. In addition, an elevated level ( 2 to $>1000$ folds) of occupational exposure to phthalate residues in various workplaces including PVC and rubber boot/hose manufacturers and nail salons implies the significances of continuous assessment of adverse effects of phthalates and its metabolite (Hines et al., 2009)

The prominent environmental occurrence, significant exposure potential, and the toxicological evidence of dialkyl ortho-phthalates ensued the permanent banning of DEHP, DBP, and BBP $(>0.1 \%)$ in children's toys and articles and an interim prohibition on DOP, DINP, and DIDP ( $>0.1 \%$ ) in children's toys in the USA (CPSIA, 2008). Therefore, select dialkyl ortho-phthalates are recently being replaced by two major classes of non-phthalate plasticizers - citrates such as ATBC and adiaptes such as DIBA and DEHA in controlled consumer products (USCPSC, 2010; Bernard et al., 2014). ATBC and DEHA are among the U.S. EPA high production volume compounds ( $>1 \mathrm{M}$ pounds produced or imported). ATBC has been primarily used in cosmetics, food contact wrappings, cables, and children's toys whereas adipates are used in building materials, vinyl floorings, carpet backing, wooden veneer, coated fabrics, and toys (EC, 2008; LCSP, 2011). Although non-phthalate plasticizers are generally considered safe alternatives to phthalate plasticizers, only very few studies focused on evaluating leachability, and toxicological impact of non-phthalate plasticizers in the environment have been reported (Fromme et al., 2016). DEHA and ATBC were previously measured at $\mu \mathrm{g} / \mathrm{g}$ levels in PVC medical devices (Gimeno et al., 2014). Recently, Fromme et al. (2016) found DEHA and ATBC in all indoor dust from 63 childcare centers in Germany at a mean concentration of $80 \mu \mathrm{g} / \mathrm{g}$ and $146 \mu \mathrm{g} / \mathrm{g}$, respectively (Fromme et al., 2016) This was the only study to report non-phthalate plasticizers in indoor dust. In addition, there is no report of phthalate and nonphthalate contamination in indoor dust from salons in the USA 
despite their occurrence in air and airborne particulates (Tran and Kannan, 2015)

This study represents the first report of non-phthalate plasticizers including DIBA, DEHA, and ATBC in indoor dust in the USA. In addition, this study also reports the phthalates for the first time in indoor dust from salons in the USA. Select plasticizer contaminants, including both legacy dialkyl ortho-phthalates (DMP, DEP, DIBP, DBP, BBP, DEHP, and DOP) and novel non-phthalates (DIBA, DEHA, and ATBC) were assessed in indoor dust samples from childcare facilities $(n=11)$ in seven states, salons $(n=5)$ in three states, and homes $(n=11)$ in five states of the USA. In addition, the daily intakes of phthalate and non-phthalate plasticizers through the dust ingestion and dermal uptake (ng/kg-bw/day) for five different age groups were estimated.

\section{Methods and materials}

\subsection{Chemicals}

Standards including DMP, DEP, DIBP, DBP, BBP, DEHP, DOP, DIBA, dimethyl phthalate-3,4,5,6- $\mathrm{d}_{4}$, diethyl phthalate-3,4,5,6- $\mathrm{d}_{4}$, di-isobutyl phthalate-3,4,5,6- $\mathrm{d}_{4}$, di-n-butyl phthalate- $\mathrm{d}_{4}$, bis-(2ethylhexyl) phthalate- $\mathrm{d}_{4}$, di-n-octyl phthalate-3,4,5,6- $\mathrm{d}_{4}$ were purchased from AccuStandard Inc. (New Haven, CT). DEHA (99\% purity) was purchased from ACROS Organics (New Jersey, USA) and ATBC ( $>97 \%$ purity) was purchased from TCI Tokyo Chemical Industries, Co Ltd. (Portland, OR). Hexane (HRGC grade), acetone (Optima; 99.7\%), and methanol (HPLC grade, 99.9\%) were purchased from Fisher Scientific (Waltham, MA).

\subsection{Sample collection}

Twelve indoor dust samples from eleven childcare facilities (four in Kentucky, two in Texas, one in Ohio, one in Indiana, one in South Dakota, one in Maryland, one in California), five indoor dust samples from salons (three in Kentucky, one in Indiana, and one in Texas), and eleven indoor dust samples from homes (four in Kentucky, two in Texas, one in Maryland, three in California, one in Massachusetts) were collected in September/October 2016. The average temperature in the month of September/October (late Summer/early Fall) in the USA can represent the annual average temperature. Samples from the vacuum cleaner were transferred directly into the aluminum foil, transported to the laboratory at Murray State University, sieved using $1.40 \mathrm{~mm}$ USA Standard Testing Sieve \#4 (W.S. Tyler Inc. Ohio, USA), and stored at $-20^{\circ} \mathrm{C}$ until further analysis.

\subsection{Sample preparation}

Approximately $0.1 \mathrm{~g}$ of indoor dust samples in glass centrifuge tubes were spiked with a mixture of internal standards (200 ng-3 $\mu \mathrm{g}$ ) and allowed to equilibrate at room temperature. Six milliliters of hexane: acetone $(1: 1 \mathrm{v} / \mathrm{v})$ was added and vortexmixed for $\sim 20 \mathrm{~s}$. The samples were extracted using ultrasonicator FS20D (Fisher Scientific, Waltham, MA) for $30 \mathrm{~min}$ and centrifuged using Centrific Model 228 (Fisher Scientific, Waltham, MA) at $3300 \mathrm{rpm}$ for $5 \mathrm{~min}$. The supernatant liquid was transferred to a clean glass centrifuge tube and the extraction was repeated. Both extracts were pooled for each sample, and was concentrated to $\sim 200 \mu \mathrm{L}$ under a gentle flow of ultra-high purity nitrogen gas (purity 99.999\%) using Reacti-Vap ${ }^{\mathrm{TM}}$ evaporator (Fisher Scientific, Waltham, MA). The concentrate was quantitatively transferred to a GC-vial and the final volume was adjusted to $1 \mathrm{~mL}$. Two microliters of prepared sample were injected for GC-MS analysis.

\subsection{Instrumental analysis}

Select non-phthalate and phthalates plasticizers were analyzed using a gas chromatograph (Agilent Technologies 7890 A) interfaced with a mass spectrometer and triple-axis detector (Agilent Technologies $5975 \mathrm{C}$ ). The analytes were separated using a capillary column (Agilent Technologies HP-5MS, $30 \mathrm{~m} \times 0.25 \mathrm{~mm}$; i.d. $0.25 \mu \mathrm{m}$ ) and ultra-high purity helium gas (purity $99.999 \%$ ) as a mobile phase. The initial oven temperature was set at $75^{\circ} \mathrm{C}$, ramped to $200{ }^{\circ} \mathrm{C}$ at a rate of $30^{\circ} \mathrm{C} / \mathrm{min}$, ramped at $3{ }^{\circ} \mathrm{C} / \mathrm{min}$ to $250{ }^{\circ} \mathrm{C}$ (held for $2.5 \mathrm{~min}$ ), ramped at $40^{\circ} \mathrm{C} / \mathrm{min}$ to $280^{\circ} \mathrm{C}$ (held for $5 \mathrm{~min}$ ), and final ramped at $80^{\circ} \mathrm{C} / \mathrm{min}$ to $300^{\circ} \mathrm{C}$ (held for $30 \mathrm{~min}$ ). The mass source, quadrupole, and injector were held at a constant temperature of $230{ }^{\circ} \mathrm{C}, 150{ }^{\circ} \mathrm{C}$, and $300{ }^{\circ} \mathrm{C}$, respectively. Target analytes were identified based on the retention time, the most abundant signature $\mathrm{m} / \mathrm{z}$ ion (also used for quantitation), the second most abundant $\mathrm{m} / \mathrm{z}$ ion (qualitative ion), and their ratio prior to the quantification using selective ion-monitoring (SIM) mode. The mass spectra and monitored $\mathrm{m} / \mathrm{z}$ ions of non-phthalate plasticizers (DIBA, DEHA, and ATBC) have been provided (Fig. 1).

The quantitation of phthalates was based on the isotope dilution method whereas the non-phthalate plasticizers and BBP were quantified using di- $n$-butyl phthalate- $\mathrm{d}_{4}$ (due to the lack of labeled standards) as an internal standard. The calibrations curves were prepared by plotting concentration-dependent response factor of each target analyte (peak area of analyte divided by peak area of internal standard) versus the response-dependent concentration factor (concentrations of analyte divided by the concentration of internal standard). The regression coefficients $\left(r^{2}\right)$ for five-to sevenpoint calibration standards calculated by linear regression were $\geq 0.99$ for all target analytes.

\subsection{Quality assurance and quality control}

The limits of quantitation (LOQs) and limits of detection (LODs) were determined as a minimum concentration of analytes that provide a signal to noise ratio $\geq 10$ and $\geq 3$, respectively. LOQs for target analytes ranged from 0.460 to $926 \mathrm{ng} / \mathrm{mL}$ whereas LODs ranged from 0.140 to $278 \mathrm{ng} / \mathrm{mL}$. The continuing calibration verification (the fifth calibration level) standard injected after every ten samples showed recoveries at $100 \pm 25 \%$. A method blank was analyzed at the beginning and the end of every batch of samples. All the analytical data presented herein are blank corrected.

One sample was selected randomly for matrix spike and matrix spike duplicate analysis, spiked with target plasticizers and their corresponding internal standards at the fifth calibration level, and were passed through the entire analytical procedure. The average relative recoveries of DMP, DEP, DIBP, and DBP were range from $100 \pm 26 \%$, however; the recoveries of other analytes could not be calculated due to the higher level of analytes in corresponding matrix blanks.

\subsection{Method validation}

The entire method was validated with a triplicate spiking and recovery experiment in a randomly selected indoor dust sample. The solvent extraction efficiencies were also evaluated for two solvents combinations [hexane: acetone $(1: 1 \mathrm{v} / \mathrm{v})$ and methanol: acetone $(1: 1 \mathrm{v} / \mathrm{v})]$. For each solvent combination, $\sim 0.1 \mathrm{~g}$ of indoor dust samples $(\mathrm{n}=3)$ were fortified with a mixture of analyte's standard solution (the fifth calibration level), processed through the entire method (as provided above), spiked with the internal standards, adjusted the final volume to $1 \mathrm{~mL}$, and analyzed. Average recoveries and relative standard deviations (RSD) were range from $91.0 \pm 5.7 \%(\mathrm{DMP})$ to $126 \pm 2.3 \%$ (DEHP) with the hexane and 


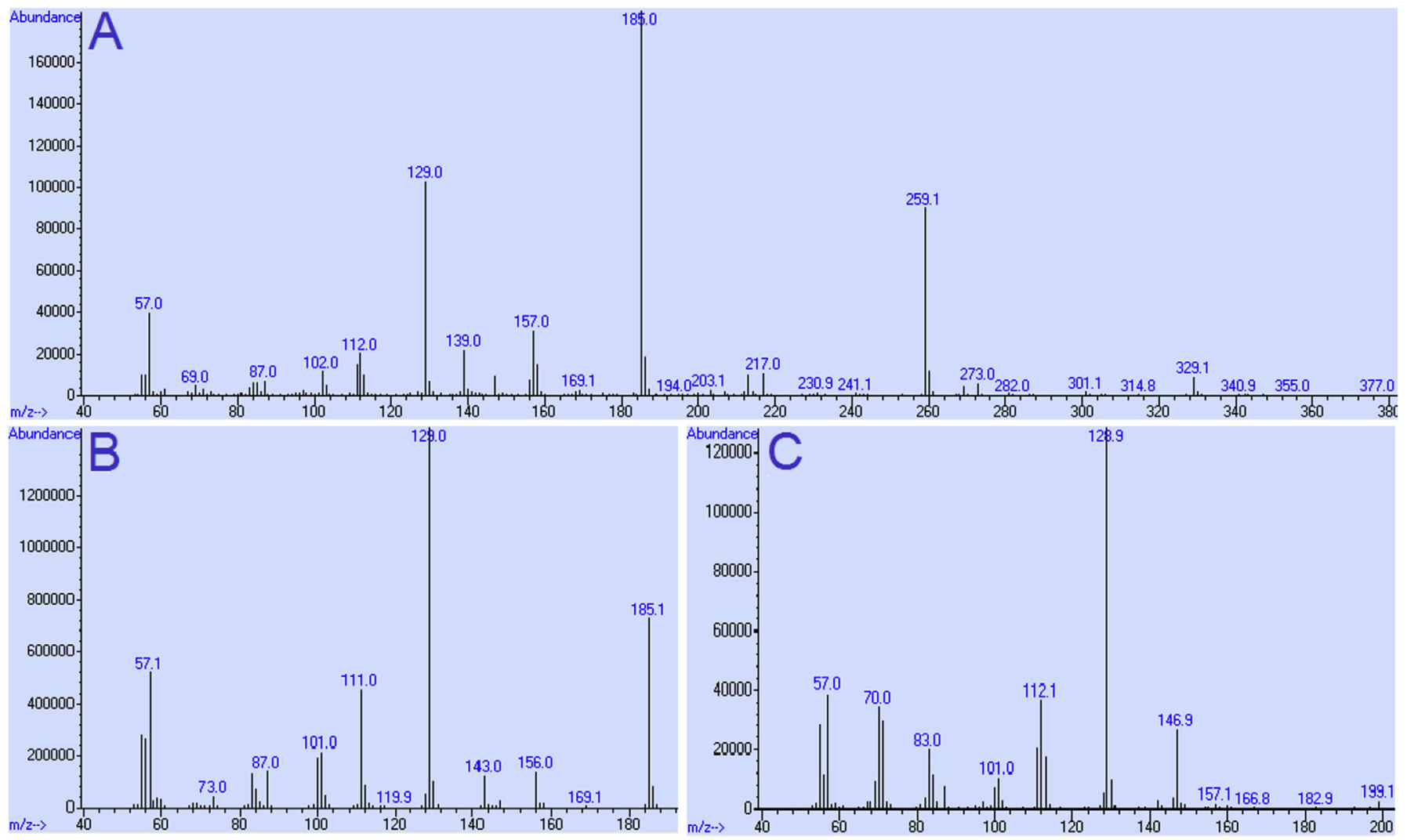

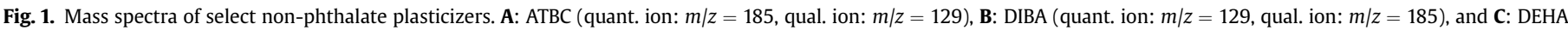
(quant. ion: $m / z=129$, qual. ion: $\mathrm{m} / \mathrm{z}=112$ ).

acetone combination while $87.7 \pm 21.9 \%$ (DMP) to $103 \pm 20.6 \%$ (DBP) with the methanol and acetone combination. However, the spiking recoveries of BBP, DOC, ATBC, and DEHA could not be calculated due to the higher levels of analytes in matrix blanks. Methanol and acetone combination, in addition to the lower recoveries of select analytes, resulted in an elevated signal background (using full scan data acquisition mode) compared to the hexane and acetone combination. Therefore, the hexane and acetone $(1: 1 \mathrm{v} / \mathrm{v})$ mixture was chosen as an extraction solvent owing to the decreased matrix interference, instrumental maintenance, and overall increased the quality of analytical data.

\section{Results and discussion}

\subsection{Plasticizers in indoor dust}

All phthalate and non-phthalate plasticizers were detected in $>80 \%$ of the 28 dust samples analyzed in this study (i.e., 12 from childcare facilities, 5 from salons and 11 from homes) from across the USA. However, DIBA and DEHA in indoor dust samples from homes were detected only in $73 \%$ and $55 \%$, respectively (Table 2). Among non-phthalates, ATBC (GM: $876 \mu \mathrm{g} / \mathrm{g}$ ) and DIBA (GM: $5.02 \mu \mathrm{g} / \mathrm{g}$ ) were found 3 to 10 times higher in salons than in childcare facilities and homes.

In general, the physiochemical properties such as $\log K_{\mathrm{oa}}$ and $\log$ $K_{\mathrm{oc}}$ of contaminants determine their partitioning in indoor dust(Ma et al., 2014). In this study, concentrations of non-phthalate plasticizer DIBA were found similar to lower phthalate plasticizers, while concentrations of ATBC and DEHA were comparable to higher phthalates DEHP and DOP (Table 2). Observed similar concentrations of DIBA and lower phthalates as well as the similar concentrations of ATBC and DEHA to higher phthalates may be attributed to their similar $\log K_{\mathrm{oa}}$ and $\log K_{\mathrm{oc}}$ values (Table 1 ). The geometric mean concentrations of ATBC were found the highest (1.1-5.0 times higher than DEHP) among all phthalates and nonphthalate plasticizers in childcare facilities, homes, and salons. It is important to note that DEHP was reportedly the most frequently detected phthalate at the highest concentration levels in childcare facilities and homes in the USA (Guo and Kannan, 2011; Rudel et al., 2003; Wilson et al., 2003), China (Kang et al., 2012), Japan (Kanazawa et al., 2010), and Germany (Fromme et al., 2004). ATBC level in indoor dust from childcare facilities $(n=11)$ in this study was two times higher than from 63 childcare facilities in Germany (Fromme et al., 2016). The observed level of contaminants (DIBA, DEHA, and ATBC) in indoor environment can be explained based on their partitioning coefficients (as discussed above); however, several other factors including the plasticizer content in consumer products and moisture content of the indoor environment can affect their concentrations. For example, despite similar $\log K_{\mathrm{oc}}$ and $\log K_{\text {oa }}$ values, the DEHA concentration in indoor dust from salons $(69.6 \pm 36.5 \mu \mathrm{g} / \mathrm{g})$ was measured 2 and 6 times lower than DOP and DEHP, respectively. It is likely that higher content of DOP and DEHP in our existing consumer products and their prominent usage resulted in observed higher concentrations of DEHP and DOP than DEHA in an indoor environment.

\subsection{Contamination profile}

ATBC or DEHP dominates the contamination profile of plasticizers in indoor dust from salons whereas ATBC or DEHA (nonphthalates) and DEHP or DOP (phthalates) were the major plasticizers in childcare facilities and homes (Fig. 2). The relative levels of 
Table 2

Concentration of phthalate and non-phthalate plasticizers $(\mu \mathrm{g} / \mathrm{g})$ in indoor dust from childcare facilities, homes, and salons across the USA.

\begin{tabular}{|c|c|c|c|c|c|c|c|c|c|c|}
\hline \multirow[t]{2}{*}{ Sampling sites } & \multicolumn{7}{|c|}{ Phthalate plasticizers } & \multicolumn{3}{|c|}{ Non-phthalate plasticizers } \\
\hline & DMP & DEP & DIBP & DBP & BBP & DEHP & DOP & DIBA & DEHA & ATBC \\
\hline \multicolumn{11}{|l|}{ Childcare facilities } \\
\hline Silver Spring, MD & 0.07 & 3.09 & 15.3 & 3.10 & 63.4 & 111 & 147 & 0.33 & 171 & 127 \\
\hline Waco, TX & 0.06 & 2.10 & 28.4 & 18.3 & 714 & 985 & 250 & 0.81 & 223 & 542 \\
\hline Waco, TX & 0.07 & 12.7 & 19.5 & 7.20 & 3080 & 555 & 249 & 0.95 & 275 & 480 \\
\hline Waco, TX & 0.06 & 0.28 & 7.44 & 2.76 & 712 & 75.0 & 36.4 & 0.44 & 25.3 & 166 \\
\hline Murray, KY & 0.18 & 0.73 & 10.2 & 11.8 & 61.3 & 317 & 98.5 & nd & 175 & 362 \\
\hline Murray, KY & 0.12 & 0.93 & 8.28 & 6.34 & 61.4 & 1950 & 108 & 0.35 & 225 & 190 \\
\hline Murray, KY & 0.11 & 2.06 & 5.96 & 3.09 & 81.6 & 54.0 & 58.5 & 0.28 & 25.9 & 124 \\
\hline Murray, KY & 0.10 & 3.13 & 25.2 & 25.7 & 143 & 690 & 112 & 0.28 & 203 & 424 \\
\hline West Lafayette, IN & 0.04 & 0.08 & 4.56 & 2.42 & 355 & 43.6 & 65.4 & 0.27 & 15.2 & 45.6 \\
\hline Hubbard, $\mathrm{OH}$ & 0.15 & 1.93 & 33.8 & 4.08 & 27.0 & 76.3 & 96.1 & nd & 30.5 & 257 \\
\hline Brookings, SD & 0.20 & 16.3 & 138 & 15.4 & 138 & 129 & 73.0 & 1.87 & 128 & 141 \\
\hline El Cerrito, CA & 0.07 & 3.08 & 15.9 & 8.20 & 60.1 & 77.1 & 664 & 0.68 & 251 & 341 \\
\hline \multicolumn{11}{|l|}{ Homes } \\
\hline Medway, MA & 0.01 & 0.09 & 1.24 & 1.55 & 52.4 & 44.8 & 6.65 & nd & nd & 24.7 \\
\hline Silver Spring, MD & 0.01 & nd & 0.32 & 0.14 & nd & 8.80 & 2.80 & nd & nd & nd \\
\hline Murray, KY & 0.04 & 0.49 & 0.92 & 0.73 & 23.8 & 11.2 & 304 & 0.36 & 21.8 & 47.5 \\
\hline Murray, KY & 0.10 & 0.32 & 2.02 & 2.24 & 52.4 & 101 & 65.7 & 1.20 & 225 & 144 \\
\hline Murray, KY & 0.11 & 0.49 & 4.08 & 11.3 & 1230 & 103 & 77.2 & 1.24 & nd & 1720 \\
\hline Murray, KY & 0.05 & 1.61 & 3.36 & 2.50 & 46.0 & 41.6 & 102 & 1.05 & 117 & 2180 \\
\hline Waco, TX & 0.07 & 15.7 & 4.60 & 4.74 & 434 & 89.3 & 74.9 & 3.33 & nd & nd \\
\hline Waco, TX & 0.07 & 2.01 & 4.89 & 5.40 & 390 & 412 & 10.8 & nd & 195 & 1340 \\
\hline San Diego, CA & 0.01 & 0.30 & 20.5 & 3.54 & 25.0 & 125 & 46.2 & 1.30 & nd & 188 \\
\hline El Cerrito, CA & 0.04 & 2.18 & 13.2 & 8.46 & 47.5 & 59.9 & 512 & 1.29 & 156 & 448 \\
\hline El Cerrito, CA & 0.03 & 2.57 & 13.5 & 5.23 & 51.2 & 73.1 & 386 & 2.35 & 133 & 271 \\
\hline \multicolumn{11}{|l|}{ Salons } \\
\hline Murray, KY & 0.11 & 0.82 & 5.63 & 3.75 & 68.2 & 159 & 148 & 28.9 & 53.9 & 562 \\
\hline Murray, KY & 0.04 & 10.8 & 3.83 & 8.92 & 55.7 & 643 & nd & 56.4 & 111 & 179 \\
\hline Murray, KY & 0.14 & 3.18 & 5.74 & 3.51 & 31.5 & 196 & 161 & 1.46 & 29.4 & 4860 \\
\hline Lafayette, IN & 0.24 & 2.09 & 26.2 & 150 & 194 & 1150 & 85.8 & nd & 81.3 & 252 \\
\hline Waco, TX & 0.02 & 2.08 & 25.6 & 16.1 & 788 & 705 & 179 & 0.27 & 114 & 4160 \\
\hline
\end{tabular}

non-phthalate plasticizers such as ATBC and DEHA are as high as DEHP in most of the childcare facilities and homes. The contamination profiles indicate unevenly distributed plasticizer residues in indoor dust in childcare facilities across the USA. However, the major non-phthalates (ATBC and DEHA) and phthalates (DEHP and DOP) account for an average of $48 \%$ and $37 \%$ of the total loads of measured plasticizers in indoor dust from childcare facilities, respectively. It is important to note that a single indoor dust sample from each childcare facility was analyzed (except two dust samples from the same childcare facility in Waco, TX). The observed similar contamination profile in two childcare rooms (with similar household products, furniture, electronics, building materials, etc) in a childcare facility in Waco, TX suggests similar sources of contamination within a facility.

The reported mean concentrations of phthalate plasticizers in airborne particulates (collected in quartz fiber filters using lowvolume air samplers) from New York were $11.7 \mu \mathrm{g} / \mathrm{g}$ (DMP) to $7570 \mu \mathrm{g} / \mathrm{g}$ (DIBP) with a contamination profile of seven most frequently detected phthalates: DIBP $>$ DEP $>$ DBP $>$ DEHP > BBP > DMP (Tran and Kannan, 2015). Similarly, Fromme et al., 2013 found the median concentrations of phthalate plasticizers (analyzed in this study) in the order of DEHP $>$ DBP $>$ DIBP $>$ BBP $>$ DEP $>$ DMP in indoor dust while DIBP $>$ DBP $>$ DEHP $>$ DEP $>$ DMP in indoor air from 63 daycare facilities in Germany. A different contamination profile observed in the current study, DEHP > DOP > BBP > DBP > DIBP > DEP > DMP, may suggest settling of airborne particulates is not the only source for accumulation of phthalates in indoor dust. The dominant contamination profile of lower phthalates in the airborne particulates observed by Tran and Kannan (2015) could result from their relatively higher vapor pressure (Table 1 ). Overall, the mean concentrations of DEHP and BBP were followed by DOP, DIBP, and DBP among phthalate plasticizers, a similar trend as was previously reported in childcare facilities (Gaspar et al., 2014) and homes (Guo and Kannan, 2011).

ATBC is a frequently used ingredient in cosmetics (Fromme et al., 2016) and was found at higher ( $49 \%$ of the total loads of measured plasticizers) and more consistent levels than DEHA followed by DEHP and DOP (35\%) in salons. Adipates are commonly used in building materials, vinyl floorings, carpet backing, wooden veneer, coated fabrics, and toys (USCPSC, 2010). In this study, DEHA and ATBC together accounted for an average of $51 \%$ of the total loads of measured plasticizers in indoor dust from homes across the USA followed by DEHP and DOP (39\%). The recent prohibition in the application of phthalate plasticizers including DEHP, DBP, BBP, and DOP in children's toys and articles in the USA (CPSIA, 2008) and Europe (EUROPA, 2005) can result in an increased usage of nonphthalate plasticizers and increased emission to the indoor environment. Further compositional analysis of consumer products from the sites of potential exposure of plasticizers including manufacturers, salons, childcare facilities, and homes may identify the source of contamination. However, relatively higher use of plasticizer-rich cosmetic products in salons may explain 3-10 folds higher concentration of ATBC and DIBA than in childcare facilities and homes. Overall, it is important to determine the residual levels of novel non-phthalate plasticizers along with the legacy phthalate plasticizers in an indoor environment, routes of exposure, daily intake, and potential effects on public health.

\subsection{Estimation of daily intake}

The daily intake of phthalate and non-phthalate plasticizers through the dust ingestion and dermal uptake (ng/kg-bw/day) for five different age groups [infants $(<1 \mathrm{y})$, toddlers $(1-6 \mathrm{y})$, children 


\section{Childcare Facilities}

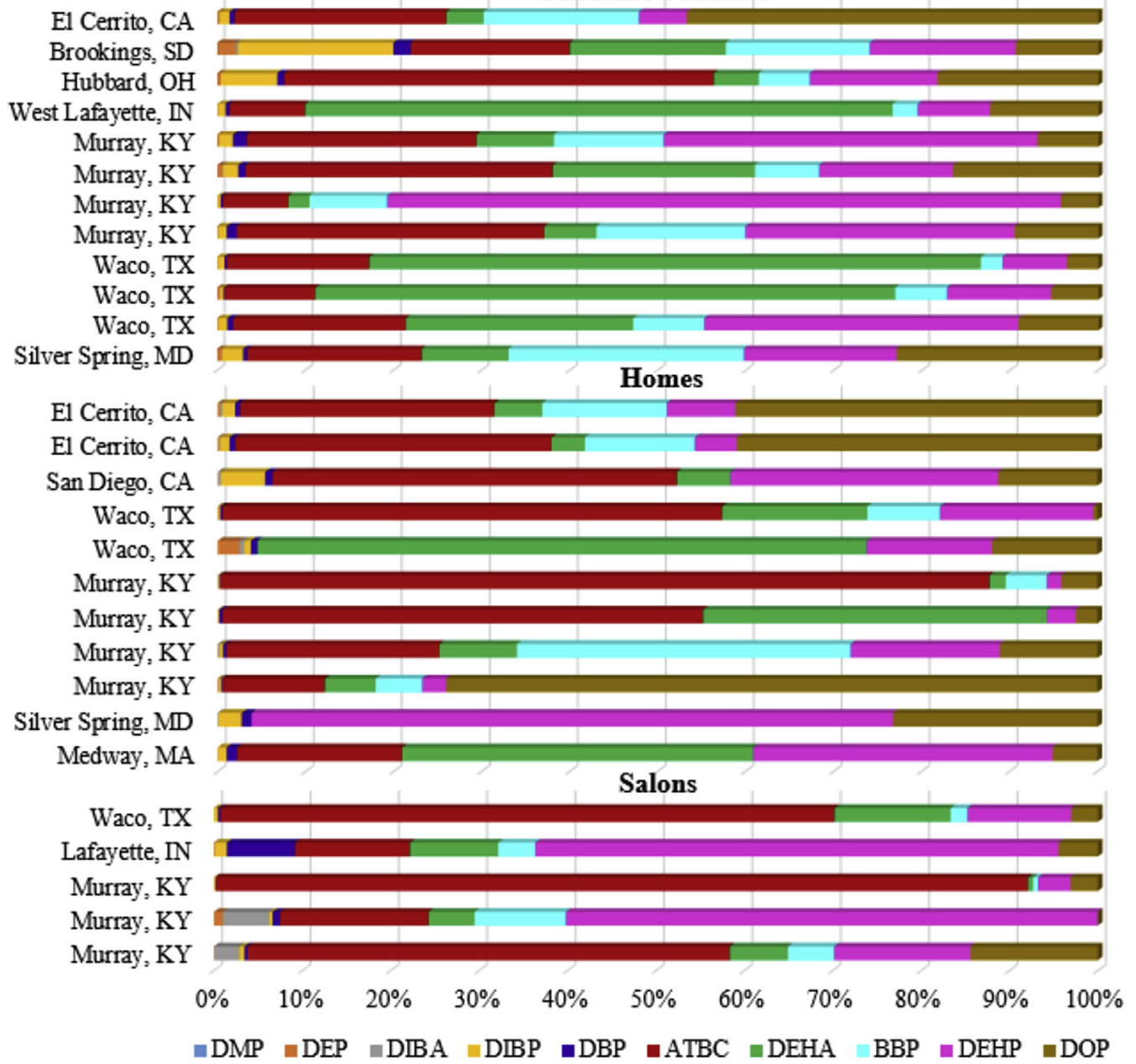

Fig. 2. Contamination profile of non-phthalate and phthalate plasticizers in indoor dust from childcare facilities, homes, and salons in the USA.

Table 3

Daily intake of phthalates and non-phthalate plasticizers (ng/kg-bw/day) from indoor dust for various age groups in childcare facilities, homes, and salons across the USA.

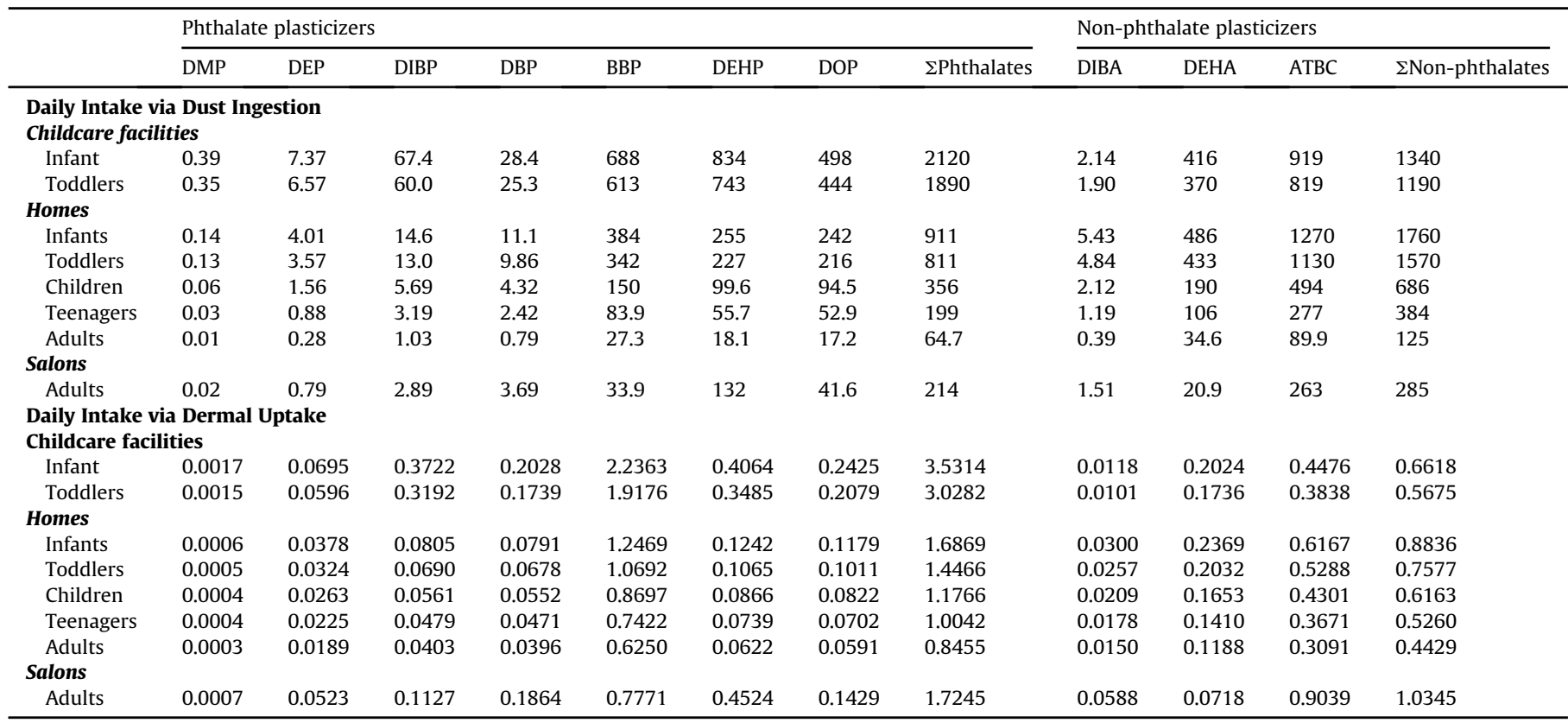


$(6-11 \mathrm{y})$, teenagers $(12-19 \mathrm{y})$, and adults $(\geq 20 \mathrm{y})]$ were estimated (Table 3) utilizing the parameters reported by Guo and Kannan (2011) and the US EPA (USEPA, 2011) as:

DI through dust ingestion $=\frac{C_{d u s t} \cdot I E F . S I R}{M_{1}}$

DI through dermal uptake $=\frac{C_{d u s t} \cdot A \cdot M_{2} \cdot I E F . P A S}{M_{1}}$

where, $C_{\text {dust }}$ is the plasticizer concentration (GM) in dust $(\mu \mathrm{g} / \mathrm{g})$, IEF is the indoor exposure fraction [infants: 0.96 ( $23 \mathrm{~h} /$ day $)$, teenagers: 0.92 ( $22 \mathrm{~h} /$ day $)$, children and teenagers: 0.88 ( $21 \mathrm{~h} /$ day $)$, and adults: 0.79 (19 h/day)], SIR is the soil ingestion rate (infants: $0.03 \mathrm{~g} / \mathrm{day}$, toddlers, children and teenagers: $0.06 \mathrm{~g} / \mathrm{d}$, and adults: $0.03 \mathrm{~g} / \mathrm{d}), M_{1}$ is the body weight (infants: $6.8 \mathrm{~kg}$, toddlers: $14.6 \mathrm{~kg}$, children: $31.8 \mathrm{~kg}$, teenagers: $56.8 \mathrm{~kg}$, and adults: $79.1 \mathrm{~kg}$ ). Similarly, $A$ is the body surface area (hands, legs, and arms that sums $25 \%$ of the total skin of infant $\left(1436 \mathrm{~cm}^{2}\right)$, toddlers $\left(2764 \mathrm{~cm}^{2}\right)$, children $\left(5130 \mathrm{~cm}^{2}\right)$, teenagers $\left(7820 \mathrm{~cm}^{2}\right)$, and adults $\left(10135 \mathrm{~cm}^{2}\right), M_{2}$ is the soil adhered to the skin $\left(0.096 \mathrm{mg} / \mathrm{cm}^{2}\right)$, PAS is the fraction of plasticizers absorbed in the skin (DMP: 0.000955; DEP: 0.002051; DIBP: 0.001202; DBP: 0.001556; BBP: 0.000707; DEHP: 0.000106). For non-phthalate plasticizers, PAS of phthalates having similar $\log K_{\mathrm{oa}}$ (DIBA: 0.001202; DEHA, ABTC, and DOP: 0.000106) were used.

The daily intake of total phthalate and non-phthalate plasticizers through dust ingestion and dermal uptake at home was found in the order of infants $>$ toddlers $>$ children $>$ teenagers $>$ adults (Table 3), which is a similar order to Guo and Kannan (2011) reported for the daily intake of phthalates in the USA. The daily intake of total phthalates $(n=7)$ by the children and toddlers through indoor dust in childcare facilities were 1.6 times higher than non-phthalate plasticizers $(\mathrm{n}=3)$ whereas the daily intakes of total non-phthalates by all age groups at home were 1.9 times higher than phthalate plasticizers. Similarly, the daily intake of total phthalates by the children and toddlers through indoor dust at childcare facilities was 2.3 fold higher than at home but the daily intake of total non-phthalates by the same age group at home was 2.3 fold higher than at childcare facilities. Overall, infants and toddlers are more vulnerable to the exposure of phthalate as well as non-phthalate plasticizers through indoor dust than teenagers and adults are. It is important to note that the estimated higher daily intake of total phthalate and non-phthalate plasticizers by infants and toddlers in this study is based only on the dust ingestion and dermal uptake. Higher daily intake per unit body mass in infants and toddlers than adults can be due to higher uptake of dust via children's more frequent hand-mouth activities. However, diet was found to be an overall major source of phthalate exposure based on the estimation of daily intake of phthalates from dietary sources as well as from biomonitoring approach (Guo et al., 2012; Fromme et al., 2013). Therefore, the total daily intake of phthalate and non-phthalate plasticizers can be different among various age groups if we consider cumulative sources of contamination including food, water, and air.

The daily intake of phthalate and non-phthalate plasticizers through indoor dust by the adults at salons ( 214 and $285 \mathrm{ng} / \mathrm{kg}$-bw/ day, respectively) was $\sim 3$ times higher than at home (Table 3 ). It indicates that the occupational exposure of an adult such as at salons can be higher than at home as suggested by Hines et al. (2009) The exposure of phthalate and non-phthalate plasticizers through the dust ingestion were found several orders of magnitude higher than dermal uptake.

\section{Conclusion}

Select phthalates and non-phthalates plasticizers were investigated in 28 dust samples collected from three different indoor environments across the USA. The mean concentrations of nonphthalate plasticizers ATBC, DEHA, and DIBA were found at $0.51-880 \mu \mathrm{g} / \mathrm{g}$ for the first time in indoor dust samples from childcare facilities, homes, and salons across the USA. The observed concentrations of these replacement non-phthalate plasticizer were as high as DEHP, the most frequently detected phthalate plasticizer at highest concentration worldwide, in most of indoor dust samples. The estimated daily intakes of total phthalates $(n=7)$ by children and toddlers through indoor dust in childcare facilities were 1.6 times higher than the non-phthalate plasticizers $(n=3)$, whereas estimated daily intake of total non-phthalates for all age groups at homes were 1.9 times higher than the phthalate plasticizers. This study reveals, for the first time, a more elevated $(\sim 3$ folds) occupational intake of phthalate and non-phthalate plasticizers through the indoor dust at salons (214 and $285 \mathrm{ng} / \mathrm{kg}-\mathrm{bw} /$ day, respectively) than at homes in the USA. Therefore, further studies determining the residual levels of novel non-phthalate plasticizers along with the legacy phthalate plasticizers in an indoor environment, routes of exposure, daily intake, and potential effects on public health would be required to evaluate the overall quality of indoor environment.

\section{Acknowledgements}

Authors gratefully acknowledge Jones/Ross Research Center at Murray State University for providing instrumental accessibility. Authors would also like to thank Dr. Daniel Johnson, Dr. Manoj Pathak, Dr. Prem Chand, Dr. Mahesh Bhatt, Dr. Thiru Munisamy, Megan-Lynn Mae Vavrinak, Subha Dahal, Mina Paudel, Sharmila Gautam Gyawali, Sudha Sharma, and Pooja Siwakoti for their assistance on sample collection.

\section{References}

Bernard, L., Decaudin, B., Lecoeur, M., Richard, D., Bourdeaux, D., Cueff, R., Sautou, V., 2014. Analytical methods for the determination of DEHP plasticizer alternatives present in medical devices: a review. Talanta 129, 39-54.

Bi, C., Liang, Y., Xu, Y., 2015. Fate and transport of phthalates in indoor environments and the influence of temperature: a case study in a test house. Environ. Sci. Technol. 49, 9674-9681.

Butte, W., Heinzow, B., 2002. Pollutants in house dust as indicators of indoor contamination. Rev. Environ. Contam. Toxicol. 175, 1-46.

Cousins, I., Mackay, D., 2000. Correlating the physical-chemical properties of phthalate esters using the 'three solubility' approach. Chemosphere 41 , 1389-1399.

CPSIA (Consumer Product Safety Improvement Act), 2008. Public Law 110-314. 122 STAT 3016-3077. https://www.cpsc.gov/s3fs-public/cpsia.pdf (Accessed on December 2016).

EU (European Commission), 2008. Scientific Committee on Emerging and Newlyidentified Health Risks: Opinion on the Safety of Medical Devicescontaining DEHP Plasticized PVC or Other Plasticizers on Neonates and Othergroups Possibly at Risk. Brussels, Belgium, 2008. http://ec.europa.eu/health/archive/ ph_risk/committees/04_scenihr/docs/scenihr_0_014.pdf (Accessed on December 2016).

EUROPA, 2005. Permanent Ban of Phthalates: Commission Hails Long-term Safety for Children's Toys. EUROPA Rapid Press Release, 2005. http://europa.eu/rapid/ press-release_IP-05-838_en.htm (Accessed on December 2016).

Fromme, H., Lahrz, T., Piloty, M., Gebhart, H., Oddoy, A., Ruden, H., 2004. Occurrence of phthalates and musk fragrances in indoor air and dust from apartments and kindergartens in Berlin (Germany). Indoor Air 14, 188-195.

Fromme, H., Lahrz, T., Kraft, M., Fembacher, R., Dietrich, L., Sievering, S., Burghardt, S., Schuster, R., Bolte, G., Volkel, W., 2013. Phthalate in German daycare centers: occurrence in air and dust and the excretion of their metabolites by children (LUPE 3). Environ. Int. 61, 64-72.

Fromme, H., Schutze, A., Lahrz, T., Kraft, M., Fembacher, L., Sievering, S., Burkardt, R., Dietrich, S., Koch, H.M., Volkel, W., 2016. Non-phthalate plasticizers in German daycare centers and human biomonitoring of DINCH metabolites in children attending the centers (LUPE 3). Int. J. Hyg. Environ. Health 219, 33-39.

Gaspar, F.W., Castorina, R., Maddalena, R.L., Nishioka, M.G., McKone, T.E., 
Bradman, A., 2014. Phthalate exposure and risk assessment in California child care facilities. Environ. Sci. Technol. 48, 7593-7601.

Gimeno, P., Thomas, S., Bousquet, C., Maggio, A.F., Civade, C., Brenier, C., Bonnet, P.A., 2014. Identification and quantification of 14 phthalates and 5 non-phthalate plasticizers in PVC medical devices by GC-MS. J. Chromatogr. B 949-950, 99-108.

Guo, Y., Kannan, K., 2011. Comparative assessment of human exposure to phthalate esters from house dust in China and the United States. Environ. Sci. Technol. 45, 3788-3794.

Guo, Y., Zhang, Z., Liu, L., Li, Y., Ren, N., Kannan, K., 2012. Occurence and profiles phthalates in foodstuffs from China and their implications for human exposure. J. Agric. Food Chem. 60, 6913-6919.

Hines, C.J., Nilsen Hopf, N.B., Deddens, J.A., Calafat, A.M., Silva, M.J., Grote, A.A., Sammons, D.L., 2009. Urinary phthalate metabolite concentrations among workers in selected industries: a pilot biomonitoring study. Ann. Occup. Hyg. $53,1-17$.

Hsu, N.Y., Liu, Y.C., Lee, C.W., Lee, C.C., Su, H.J., 2017. Higher moisture content is associated with greater emissions of DEHP from PVC wallpaper. Environ. Res. $152,1-6$.

Hutter, H.P., Haluza, D., Piegler, K., Hohenblum, P., Frohlich, M., Scharf, S., Uhl, M. Damberger, B., Tappler, P., Kundi, M., Wallner, P., Moshammer, H., 2013. Semivolatile compounds in schools and their influence on cognitive performance of children. Int. J. Occup. Med. Environ. Health 26, 628-635.

Jeon, S., Kim, K.T., Choi, K., 2016. Migration of DEHP and DINP into dust from PVC flooring products at different surface temperature. Sci. Total Environ. 547, $441-446$.

Kanazawa, A Saito, I., Araki, A, Takeda, M. Ma, M. Saijo, Y, Kishi, R, 2010. Association between indoor exposure to semi-volatile organic compounds and building-related symptoms among the occupants of residential dwellings. Indoor Air 20, 72-84.

Kang, Y., Man, Y.B., Cheung, K.C., Wong, M.H., 2012. Risk assessment of human exposure to bioaccessible phthalate esters via indoor dust around the Pearl River Delta. Environ. Sci. Technol. 46, 8422-8430.

Kay, V.R., Bloom, M.S., Foster, W.G., 2014. Reproductive and developmental effects of phthalate diesters in males. Crit. Rev. Toxicol. 44, 467-498.

Kay, V.R., Chambers, C., Foster, W.G., 2013. Reproductive and developmental effects of phthalate diesters in females. Crit. Rev. Toxicol. 43, 200-219.
Kolarik, B., Bornehag, C.-G., Naydenov, K., Sundell, J., Stavova, P., Nielsen, O.F., 2008 The concentrations of phthalates in settled dust in Bulgarian homes in relation to building characteristic and cleaning habits in the family. Atmos. Environ. 42, 8553-8559.

LCSP (Lowell Center for Sustainable Production), 2011. Phthalates and Their Alternatives: Health and Environmental Concerns. University of MassachusettsLowell, Lowell, MA. http://www.sustainableproduction.org/downloads/ PhthalateAlternatives-January2011.pdf (Accessed on December 2016).

Liu, Q.T. Chen, R. McCarry, B.E., Diamond, M.L., Bahavar, B., 2003. Characterization of polar organic compounds in the organic film on indoor and outdoor glass windows. Environ. Sci. Technol. 37, 2340-2349.

Ma, W., Subedi, B., Kannan, K., 2014. The occurrence of bisphenol A, phthalates, parabens and other environmental phenolic compounds in house dust: a review. Curr. Org. Chem. 18, 2182-2199.

Mendell, M.J., Heath, G.A., 2005. Do indoor pollutants and thermal conditions in schools influence student performance? A critical review of the literature. Indoor Air 15, 27-52.

Rudel, R.A., Camann, D.E., Spengler, J.D., Korn, L.R., Brody, J.G., 2003. Phthalates alkylphenols, pesticides, polybrominated diphenyl ethers, and other endocrinedisrupting compounds in indoor air and dust. Environ. Sci. Technol. 37, 4543-4553.

Tran, T.M., Kannan, K., 2015. Occurrence of phthalate diesters in particulate and vapor phases in indoor air and implications for human exposure in Albany. New York, USA Arch. Environ. Contam. Toxicol. 68, 489-499.

US CPSC (United States Consumer Prodcution Safety Commission), 2010. Review of Exposure and Toxicity Data for Phthalate Substitutes. https://www.cpsc.gov s3fs-public/phthalsub.pdf (Accessed on December 2016)

US EPA (United States Environment Protection Agency), 2011. Exposure Factor Handbook. EPA/600/R-090/052F. https://cfpub.epa.gov/ncea/risk/recordisplay. $\mathrm{cfm}$ ?deid $=236252$ (Accessed on December 2016).

Whitehead, T., Metayer, C., Buffler, P., Rappaport, S.M., 2011. Estimating exposures to indoor contaminants using residential dust. J. Expo. Sci. Environ. Epidemiol. 21, 549-564.

Wilson, N.K., Chuang, J.C., Lyu, C., Menton, R., Morgan, M.K., 2003. Aggregate exposures of nine preschool children to persistent organic pollutants at day care and at home. J. Expo. Anal. Environ. Epidemiol. 13, 187-202. 